\title{
Challenges in designing seamless-learning scenarios: affective and emotional effects on external representations
}

\author{
Nuno Otero* \\ Department of Information Systems, \\ University of Minho, \\ Guimarães 4800-058, Portugal \\ E-mail: nuno.otero@dsi.uminho.pt \\ *Corresponding author
}

\section{Marcelo Milrad}

Department of Computer and Information Science,

Linnaeus University,

Kalmar SE-391 82, Sweden

E-mail: marcelo.milrad@lnu.se

\section{Yvonne Rogers}

Department of Mathematics and Computing,

Open University,

UK

E-mail: Y.Rogers@open.ac.uk

\section{António J. Santos, Manuela Veríssimo and Nuno Torres}

\author{
UIPCDE, \\ ISPA Instituto Universitário, \\ Portugal \\ E-mail: Antonio.Santos@ispa.pt \\ E-mail: mveriss@ispa.pt \\ E-mail: nmtorr2@googlemail.com
}

\begin{abstract}
In this paper, we revisit different theoretical and conceptual issues that have been influencing the design of educational technology artefacts. In particular, we take into consideration recent perspectives in cognitive science that acknowledge the important effects of external representations (ERs) in learning and discuss the challenges regarding the applicability of these ideas in connection to seamless-learning environments. Extending the previous work revised here, this paper suggests that in order to further understand the nature of learning in these novel contexts, research needs to investigate how socioaffective factors come to the fore and influence the co-construction and use of ERs 'in the wild'.
\end{abstract}

AU:

Kindly check the insertion of 'Guimarães 4800-058' and 'Kalmar SE-391 82' in the affiliation.

AU:

Kindly provide city, state and zip code for Y. Rogers,

A.J. Santos, M. Veríssimo and

N. Torres. 
Keywords: external representations; collaborative learning; seamless learning; ubiquitous systems; affects; emotions; group dynamics.

Reference to this paper should be made as follows: Otero, N., Milrad, M., Rogers, Y., Santos, A.J., Veríssimo, M. and Torres, N. (xxxx) 'Challenges in designing seamless-learning scenarios: affective and emotional effects on external representations', Int. J. Mobile Learning and Organisation, Vol. x, No. $\mathrm{x}, \mathrm{pp} \cdot \mathrm{xx}-\mathrm{xx}$.

Biographical notes: Nuno Otero is a Senior Research Fellow at the University of Minho. He has a PhD in Computer Science from the University of Sussex, UK. His more specific current research interests include the design of learning technologies, situated displays and human-robot interactions. Generally, he is interested on theories and conceptual frameworks in HCI, from more traditional approaches taking a user-centred perspective to more recent trends focusing on users' experiences with technologies.

Marcelo Milrad is a Full Professor of Media Technology at the School of Computer Science, Physics and Mathematics at Linnaeus University (LNU) in Sweden. He is also the Director of the Center for Learning and Knowledge Technologies (CeLeKT). His current research interests include the design of learning environments to support learning about complex domains, collaborative discovery learning and the development of mobile and wireless applications to support collaborative learning and intellectual work. He teaches undergraduate courses in media technology and computer science with a special focus on XML, web 2.0 and mobile technologies. He also teaches Doctoral Courses in the field of technology-enhanced learning. He has published over 115 articles in international journals, refereed conferences, books and technical reports.

Yvonne Rogers is Professor of Human-Computer Interaction in the Department of Computing at the Open University, where she Directs the Pervasive Interaction Lab. From 2003 to 2006, she had a joint position in the School of Informatics and Information Science at Indiana University (USA). Prior to that, she was a Professor in the Former School of Cognitive and Computing Sciences at Sussex University. She has also been a Visiting Professor at Stanford, Apple, Queensland University and UCSD. Her research focuses on augmenting and extending everyday learning and work activities with a diversity of interactive and novel technologies. Central to her work is a critical stance towards theory and conceptual frameworks. She was one of the principal investigators on the UK Equator project (2000-2007), where she pioneered and experimented with ubiquitous learning. She has published widely, beginning with her PhD work on graphical interfaces in the early 1980 s to her most recent work on public visualisations and behavioural change. She is one of the authors of the best-selling textbook Interaction Design: Beyond Human-Computer Interaction and more recently Being Human: Human Computer Interaction in the Year 2020.

António J. Santos holds a $\mathrm{PhD}$ from the Université du Québec à Montreal. Currently, he is an Associated Professor of Research Methods at ISPA, Instituto Universitário. His major area of research is the study of preschool and primary school children's cohesive organisation.

Manuela Veríssimo achieved her PhD at the Université du Québec à Montreal. She is interested in parent-child relations. Currently, she is an Associated Professor of Developmental Psychology at ISPA, Instituto Universitário. 


\begin{abstract}
Nuno Torres graduated in Psychology in 1995 in Lisbon at ISPA and completed his PhD in Psychoanalytic Studies in 2008 at the C.P.S., University of Essex, UK. He returned to Lisbon for a Postdoctoral Fellowship in ISPA. His research interests include in biopsychosocial models integrating psychoanalytic and developmental theories to understand the developmental pathways to disorders of affect regulation and associated symptoms. Presently, he is focusing on the assessment of the different social systems and structures in which children develop: primary relationships with parents (attachment), establishment of a secure base for exploration of the environment and autonomous interactions with peers in preschool and school periods.
\end{abstract}

\title{
1 Introduction
}

The design of educational technologies has been informed by a wide range of distinct theoretical approaches (Spikol and Milrad, 2008). Recent theories and conceptual frameworks have been emphasising not only the important role of in situ social interactions between the learning actors and the available environment, but also the emergent and constructive nature of the learning. Learners are active agents of the learning process and not passive absorbers of pre-constructed knowledge.

Chan et al. (2006) have proposed to use the term 'seamless learning' for activities marked by a continuity of learning experiences across different learning contexts supported by the new affordances provided by mobile and ubiquitous technologies. Seamless learning implies that students can learn whenever they are curious in a variety of situations and that they can switch from one scenario to another easily and quickly, possibly using their personal mobile device as a mediator. These scenarios may include learning individually, with another student, a small group or a large online community, with possible involvement of teachers, relatives, experts and members of other supportive communities, face-to-face or in different modes of interaction and at a distance in places such as classroom, outdoors, parks and museums. These contexts consist of configurations of activities, material resources and relationships that are found in co-located physical or virtual spaces, providing novel opportunities to support learning.

Considering the wide range of possible scenarios and the corresponding facilitating artefacts/technologies, it seems very important to clearly understand how to design these same artefacts and technologies to support learners' effective transitions between scenarios (Looi et al., 2009). Keeping in mind the importance of the transitions between scenarios and the technological means to foster meaningful integration of learning experiences, mobile devices and applications play an important part in seamless-learning scenarios (Looi et al., 2009). This new type of collaborative tools can potentially emphasise the role that body and experience play in learning processes, providing continuity between learning experiences, as well as enabling learners to make connections between what they are observing, collecting and accessing, and thinking about over time, place and people (Rogers and Price, 2009). Moreover, effective seamless-learning scenarios can facilitate the establishment of connections between concrete and hands-on experiences, formalisms, symbolic representations and semantic concepts across different learning situations outside and inside the classroom (Sharples et al., 2009; Spikol and Milrad, 2008). In fact, learning has always occurred outside classroom walls. However, mobile technologies and ubiquitous systems can provide 
additional means to promote fruitful constructions of knowledge across time and space, and foster connections between learning experiences.

From the seamless-learning perspective, learners are given the opportunity to collaborate and interact in new ways within their peers and the physical world, as well as the physical world can be augmented through the use of digital technologies. Learners should be encouraged to externalise their learning experiences and increase their awareness of the underlying connections between abstract representations and concrete experiences. In turn, such process of externalisation should foster understanding regarding abstract thinking, generalisation and representational use. In line with these ideas, Looi et al. (2009) propose that seamless learning can be framed according to the guiding principles of distributed cognition theory. By doing so, they emphasise the need to take consideration that learning is distributed across individuals, time and space.

Cognitive processes involve an interplay between knowledge in the head and in the world (see Salomon (1993b) for a collection of distributed cognition perspectives applied to learning). Salomon (1993a) and Dillenbourg et al. (1999) discuss the nature of the distribution of cognition and learning processes, highlighting the need to understand the interconnections between individual cognitive processes (what the solo learner acquires/learns), group processes (what the social interactions foster) and contributions that specific artefacts bring to the overall process. Hence understanding the dynamics of this interplay leads to research that investigates how the design of 'knowledge in the world' affects the cognitions - in other words, how external representations (ERs) facilitate or hinder cognitive activities (Scaife and Rogers, 1996). From the point of view of cognitive science, ERs can be defined as structure and knowledge in the world, like physical symbols, objects and dimensions, external rules, constraints for action or embedded relations in physical configurations (Zhang, 1997).

However, the design of efficient ERs for computational artefacts to support the learning is, on itself, a challenge (Scaife and Rogers, 1996; Tversky et al., 2002). Furthermore, solo or collaborative-learning activities pose diverse challenges to the design of ERs and considering that seamless learning envisions a wide palette of scenarios, it seems very plausible to assume that some particular issues will arise.

One issue that, we believe, deserves further attention concerns how the distinct socioaffective dynamics of solo and group-learning activities might influence the design of seamless-learning scenarios and activities. In particular, we ask ourselves to what extent distinct socio-affective dynamics interplay with ERs. More specifically, in this paper, we take a look at how socio-affective issues present 'in the wild' might have an effect on the use and co-construction of ERs in seamless-learning scenarios. For instance, taking into consideration the need to particularly attend to issues related to the transitions between learning situations (across time and space), the cost and benefits of engaging in learning collaborations, and the influence that solo and group-learning situations have in each other, the following questions can easily come to mind:

- To what extent do conflicts, jealousy and disliking of one another have a negative impact on learning? Are these phenomena clearly reflected on the use and coconstruction of ERs? How does the use of a particular type of ER in a certain situation influence its use in another situation?

- Is it the case that children will collaborate better using and co-constructing ERs when they know each other better and work together over a long period of time? Or is it 
possible that too much friendship leads to lack of critical thinking? How can ERs encourage argumentation and critical thinking across learning scenarios?

- Is it possible to understand which ERs work better under particular socio-affective conditions? Can we design supportive tools that facilitate the learning with distinct ERs in distinct socio-affective situations (or even promote transitions between more productive socio-affective states/situations)?

- Do the interactions within groups influence what a learner can do in a solo situation, and if so, in what ways?

Sections 2 and 3 describe some conceptual aspects related to ERs and the possible influence that affective and emotional factors may have in ERs use and co-construction. Section 4 presents some challenges facing the design of computational tools to support seamless learning, emphasising the need to acknowledge the possible effects of different types of ERs and the rich socio-affective dynamics in which the learning activities are embedded. Finally, in Section 5, concluding remarks are drawn and future steps are put forward.

\section{The use and co-construction of ERs}

Cox (1999) suggests that the correct use of an ER is dependent on a complex interaction between the properties of the representation, the characteristics of the task and individual differences, such as previous knowledge and cognitive style.

Several studies focused on the role ERs (static vs. interactive diagrams, animations, virtual environments) can play in learning activities (e.g. Ainsworth et al., 1998; Arcavi, 2003; Bodemer et al., 2004; Brna et al., 2001; Cheng, 1999; Cox, 1999; Lowe, 2003; Otero et al., 2001; Scaife and Rogers, 1996). However, demonstrating the effects and details of these complex interactions between ERs and learning activities is not easy. In addition, most of the interactive learning environments usually employ more than one type of ER, making the problem space become even more complex. Research needs to account how different ERs combine, looking for synergies and clearly justify cost/benefits of using multiple ERs in learning/teaching systems (see Ainsworth, 1999; Ainsworth and VanLabeke, 2004).

Regarding collaborative use and co-construction of ERs, Stahl (2002) argues that understanding the nature and properties of the artefacts produced give valuable hints concerning the knowledge the group was able to 'acquire' along the learning activities. Hausmann et al. (2004) consider co-construction as a group process of knowledge building, involving not only active elaboration by the group members, but also critical evaluation of their contributions.

Processes of co-construction are affected by the type of artefacts and ERs that mediate the group interactions (see Brna and Burton, 1997; Healey et al., 2002a,b; Suthers and Hundhausen, 2002). For example, Fischer and Mandl (2005) analyse how ERs tools influence processes of knowledge convergence in collaborative-learning scenarios. They stress the importance of knowledge convergence within collaborative learning and consider two distinct aspects: process convergence and outcome convergence. The term 'process convergence' relates to the fact that learners influence each other when immersed in collaborative-learning activities: degree of 
acknowledgement of each other's contributions; sharing and discuss available resources (or not); the building up of joint attention and common ground. Outcome convergence concerns the possible construction of similar/common knowledge representation. Their empirical study compared how content-specific or content-independent ERs support tools, as well as type of collaboration (videoconferencing or face-to-face), impacted in process and outcomes convergence. The results suggest strong convergence regarding processes but weak on the outcomes. Furthermore, although learners using contentspecific ER were able to utilise more appropriate knowledge resources, the sharing after collaboration was not evident. The authors also report that some evidence was found for a relation between aspects of the collaborative process and knowledge convergence.

The point being highlighted in this section is that ERs have an impact on how people collaborate, co-construct knowledge and organise their learning experiences. However, the design of technological tools and digital media to support collaboration and communication in seamless-learning environments is challenging not only because the learners may be separated by time and space, but also because they may not be sharing the same learning physical context and representations. Establishing common ground and mutual understanding, two important ingredients for collaborative learning, become key points.

\section{Socio-affective and emotional factors influencing ERs co-construction and use}

Contemporary theories of cognitive development and knowledge acquisition not only emphasise contextual-cultural processes instead of universal information-processing laws (Rogoff, 2003), but also increasingly focus on micro-social interactive processes.

Vygotsky (1978) argued for the socio-cultural origins of cognitive development and learning. From his perspective, children's cognitive development is socially rooted in the sense that it occurs first in an interpersonal context, and only later becomes integrated on a personal psychological plane. Authors like Youniss (1982) underlined the Piagetian notions of cognitive development facilitation associated with close and intimate interpersonal relations. In order to conceptualise children's learning processes in social contexts, increasing attention is due to relational processes which are in turn greatly dependent on socio-affective exchanges.

The term 'socio-affective' (or socio-emotional) refers to social determinants of behaviour that are rooted in interpersonal emotional dynamics, such as empathy, coercion and exchanges of positive and negative affect. In contrast, social-cognition denotes the processing of social information by means of representations and meta-representations of the self and other's states of mind. In recent years, developmental research has highlighted the centrality of emotion-cognition integration in normative development (e.g. Sroufe, 1997). Parkinson et al. (2005) review the research themes concerning emotional factors in social relations, demonstrating the importance and vitality of this research field.

Developmental processes on both the cognitive and affective domains underlie children's capacity for cooperation and collaboration with peers, which become manifest in increasingly complex social behaviour strategies. The competent integration of cognition, affect and behaviour in a social setting can been labelled under the term 'social competence' (e.g. Rubin and Rose-Krasnor, 1992; Waters and Sroufe, 1983). The

AU:

Youniss

(1980) has

been changed

to Youniss

(1982) in the

text as per the

list. Please

check. 
collaborative use, mentoring and sharing of external objects in groups of children can be seen as partially determined by the social competence of the actors, in the sense that social competence mediates conflicts between individuals and its successful resolution. Operational models for developmental research of social competence have defined it as a broadband of correlated emotional, cognitive and behavioural attributes that result in the readiness to respond to the complex constraints and opportunities afforded by social situations, and adequately balancing the goals of the self and others (Bost et al., 1998; Waters and Sroufe, 1983).

Research has shown that children who are competent with peers, can form and maintain positive associations with others, and this entails the initiation of pro-social behaviours, such as sharing, empathy and the reciprocal expression of positive affect (e.g. Hartup and Mussen, 1983; Hinde, 1979). In addition, ER use can be seen as environmental resources of a specific context, and hence its use can be addressed also in the perspective of strategies for resource control and social domination in groups of children, such as aggressive behaviour strategy (monopolising, threatening, assaulting), and pro-social behaviour strategy (reciprocation, alliance formation, cooperation) (Hawley, 2002; Vaughn and Santos, 2008). Furthermore, in Section 2, the work by Fischer and Mandl (2005) clearly indicates that ERs tools play a role in terms of processes and outcomes of collaborative-learning activities.

According to Jones and Issroff (2005), research on collaborative learning and educational technologies need to take into account the interaction between cognitive, social and affective/emotional factors. They highlight the following issues:

- Social affinity between partners: some studies suggest that friendship relationships facilitate the communication processes and interaction regulation that in turn increase motivation and collaboration.

- Actual and perceived cognitive abilities of the partners: this factor draws the attention to possible difficulties managing asymmetries in collaboration.

- Distribution of control: another important issue concerns the way the different members of a learning group are able to control their learning pace and how available tools enable this process during collaboration.

- Nature of the task:- the nature of the task also influences the way a group 'decides' to collaborate. The difficulties of being able to collaborate synchronously might lead to losses in the activities which increase the chance of demotivation towards group work.

- Time: socio-affective relationships evolve in time. Thus, it is important to conduct longitudinal studies in order to reveal how the different elements of a group are able to appropriate the technologies at their disposal.

Summarising, different types of computational artefacts and ERs can influence the learning, not only solo learning but also collaborative-learning activities. In turn, it seems reasonable to assume that not only collaborative learning is affected by socio-affective factors, but also that ERs use and co-construction should reflect a complex interaction between group dynamics and ERs properties. 


\section{Some challenges for the design of seamless-learning scenarios}

We assume that mobile and ubiquitous technologies seem to be particularly suited for supporting embodied learning activities in diverse physical and social contexts and promote seamless-learning experiences. M-learning tools will enhance learning experiences 'on the move', fostering learning outside constrained environments of classroom teaching and facilitate continuity across learning experiences and contexts (Sharples et al., 2009). Furthermore, Rogers and Price (2009) suggest the following three main benefits of utilising mobile tools for learning: using mobile devices in the 'wild' can foster learners' motivation and engagement; these tools might increase children's participation in the ongoing learning activities and develop social and cognitive processes; mobile tools increase children's exposure to different forms of information flow and management. However, in their paper, Rogers and Price (2009) also highlight three main challenges as described below:

- Avoiding information overload:

- When to bring the critical information to the learners' attention?

- How to facilitate the integration of information from multiple sources, contexts or even dispersed in time?

- How to encourage meaningful collection of information (grounded in the children's experiences) and support relevant abstractions (giving the 'big picture')?

- Avoiding children being distracted by the devices per se:

- How should the learning activities be designed in order to minimise the risk of focusing the children's attention in the novelty of the device?

- How to design the activity in order to take into account the children's own pace of reflection? The devices should not be constantly demanding attention and distract from content.

- Understand how to constraint the learning experience in order to encourage collaboration in naturally open social contexts:

- How to design the learning activity so that it reflects some kind of strategy for device sharing and structuring of distinct children's roles in order to encourage collaboration and all socio-cognitive processes associated with it?

In Section 4.1, we describe an illustrative seamless-learning scenario that addresses some of the issues and the challenges discussed above.

\subsection{An illustrative scenario}

John is a fourth year primary school student with a preference for natural science topics. He likes to observe and collect specimens of plants and observe the behaviour of animals. His parents have been encouraging him to gather information about these issues in John's daily musings at the garden and park. John's teacher, Ms H., also noted his interests and is trying to show him the importance of simples maths for the understanding of his investigations: organizing his observations, quantifying certain parameters and creating graphs 
to elucidate the different phenomena under observation. John does not have an inclination towards mathematics.

Luke another of Ms H. pupils, on the other hand, loves maths but does not seem very interested in the science topics. In fact, whenever the daily school topic deviates from "something to do with numbers" Luke's focus of attention is lost and sometimes assumes disruptive behaviours.

In the classroom, Ms H. sometimes forms small groups of children to work in specific projects according to the themes being covered. The current topic of exploration concerns the understanding of the basic principles behind photosynthesis. Her idea is to combine data collection and direct observation of "real" experiments with the utilization of mobile devices and sensors combined with a computer simulation tool. The "real" experiments will be conducted in the classroom, at the local science museum and, if possible, in the children's homes with simple kits for growing beans. The computer simulation tool is an online tool that allows children to set up the parameters of a greenhouse environment and collect data regarding the growth and development of a specific plant. Another interesting feature of this software is the possibility to "feed" the simulation with real data. Ms H. is quite curious about the possibility of the children setting their simulation environments as a way to test some of the observations they are making of the experiments. Furthermore, Ms H. wanted the children to be able to write final reports so that these could be included in the monthly school's activities repository, which was being shared with other local schools.

For the setting of the different groups, Ms H. thought that Luke and John could be complimentary partners, but unfortunately they did not tend to play together. However, she had noticed that Sara, a quite sociable girl, might be able to establish a link. Sara liked to write stories, to draw and to take photos.

Ms H. was quite curious about how these three children could work together and truly collaborate. More than just allowing them to co-ordinate their own interests she wanted the children to understand the value of their particular skills and to be able to appreciate the importance of the different underlying subjects: be able to experiment, observe, quantify, discuss, write and report in an engaging manner. She knew each of them would bring things from home and was wondering to what extent the children would be able to integrate the different pieces of information and experiences in a school context. Furthermore, she was aware that she needed to be attentive to the way the boys would tend to highlight their own competences and, maybe, take control of the tools at their disposition: the smart phone with a high definition digital camera and some sensors to sense and record information from the science museum installation. Ms H. wondered if the best approach could be to make Sara lead the first activity by asking the group to write an initial report with photos about the available resources and possible problems. This way the boys would not be focused on their particular strengths and, probably, the writing of text would not expose, too much, their differences.

This simple scenario tries to highlight some specific instances of the kind of problems being addressed in this paper: use of tools and distinct ERs, children's distinct interests and corresponding chances for being involved in learning situations, socio-affective issues that might influence collaboration and the teachers' daily management of such factors. We believe that acknowledging the importance of socio-affective issues in this type of learning scenarios (that we envisioned to be more and more of a seamless nature) can lead to a decisive further understanding of how learning 'in the wild' occurs. 
However, such research endeavour poses challenges in terms of methodologies and methods to capture the richness of the interactions and transactions.

\section{Discussions and future steps}

In addition to the challenges identified by Rogers and Price (2009) and discussed in Section 4, we would like to stress the importance of understanding how socio-affective processes may have an effect on collaborative-learning situations that take place in seamless-learning scenarios. We believe that the very own nature of seamless learning makes socio-affective processes more prominent, since different physical and social constraints occur across distinct contexts at different times. Moreover, learners, teachers and learning facilitators will probably have to engage in complex social interactions, using a variety of tools/artefacts in order to find common ground and foster learning activities. To take full advantage of the benefits of seamless learning, these aspects need to be better understood so better supporting tools/artefacts can be devised. The envisioned research questions we intend to initially pursue to kick-start this line of investigation are the following:

- How do friendship relationships affect the collaborative process, use and coconstruction of ERs? Will these possible effects have an impact on the learning? How? What mechanisms can be implemented to facilitate the learning?

- Is it possible that the groups' socio-affective dynamics influences the perception of the group members' cognitive abilities? If yes, then it is also plausible that such phenomena might have an effect on how the group chooses the type and explicitness of the ERs. How can computational artefacts trace such issues and facilitate group management?

- Different levels of affinity might lead to distinct strategies of group co-ordination and collaboration. To what extent is it possible to create artefacts (and corresponding supporting ERs) that encourage participation and maintain knowledge coherence?

- The type of ER and its corresponding levels of explicitness and ambiguity that a group chooses for a certain problem/task might reflect the dynamics of the socioaffective factors. For example, will a group tend to 'cover' divergent opinions regarding the solution to a problem by constructing less-explicit ERs?

Furthermore, we will also explore how recent pedagogical ideas, namely situated embodiment (Barab et al., 2007) can inform the investigation of the above questions. In fact, this particular pedagogical approach seeks to engage learners to explore and experiment with multiple representations of the causal interactions and functional relationships in the topics of study as a way of promoting a deeper understanding of the domains under exploration, and to advance their interest, social engagement and motivation to learn more about these topics in the future.

To summarise, seamless learning takes advantage of the opportunities of mobile and ubiquitous technologies for providing rich contextual information during the learning experience across a variety of learning settings. As we will continue to carry out our research and to start to conduct some initial experiments, we will gain a richer understanding of the implications of socio-affective factors for improving the design and 
implementation of seamless-learning scenarios. More broadly, we hope that further investigations will help us to develop a richer theoretical framework for understanding the effects of affective and emotional factors may have on ERs that emerge in these emerging learning environments.

\section{References}

Ainsworth, S. (1999) 'A functional taxonomy of multiple representations', Computers and Education, Vol. 33, Nos. 2-3, pp.131-152.

Ainsworth, S. and VanLabeke, N. (2004) 'Multiple forms of dynamic representation', Learning and Instruction, Vol. 14, No. 3, pp.241-255.

Ainsworth, S., Wood, D. and O'Malley, C. (1998) 'There is more than one way to solve a problem: evaluating a learning environment that supports the development of children's multiplication skills', Learning and Instruction, Vol. 8, No. 2, pp.141-157.

Arcavi, A. (2003) 'The role of visual representations in the learning of mathematics', Educational Studies in Mathematics, Vol. 52, No. 3, pp.215-241.

Barab, S.A., Zuiker, S., Warren, S., Hickey, D., Ingram-Goble, A., Kwon, E-J., Kouper, I. and Herring, S.C. (2007) 'Situationally embodied curriculum: relating formalisms and contexts', Science Education, Vol. 91, pp.750-782.

Bodemer, D., Ploetzner, R., Feuerlein, I. and Spada, H. (2004) 'The active integration of information during learning with dynamic and interactive visualisations', Learning and Instruction, Vol. 14, No. 3, p.341.

Bost, K., Vaughn, B., Washington, W., Cielinski, K. and Bradbard, M. (1998) 'Social competence, social support, and attachment: demarcation of construct domains, measurement, and paths of influence for preschool children attending head start', Child development, Vol. 69, No. 1, pp.192-218.

Brna, P. and Burton, M. (1997) 'Modelling students collaborating while learning about energy', Journal of Computer Assisted Learning, Vol. 13, No. 3, pp.194-205.

Brna, P., Cox, R. and Good, J. (2001) 'Learning to think and communicate with diagrams: 14 questions to consider', Artificial Intelligence Review, Vol. 15, No. 1, pp.115-134.

Chan, T.-W., et al. (2006) 'One-to-one technology-enhanced learning: an opportunity for global research collaboration', Research and Practice in Technology Enhanced Learning, Vol. 1, No. 1, pp.3-29. DOI: 10.1142/S1793206806000032.

Cheng, P.C.H. (1999) 'Interactive law encoding diagrams for learning and instruction', Learning and Instruction, Vol. 9, No. 4, pp.309-325.

Cox, R. (1999) 'Representation construction, externalised cognition and individual differences', Learning and Instruction, Vol. 9, No. 4, pp.343-363.

Dillenbourg, P. (1999) 'What do you mean by collaborative learning? Collaborative-Learning: Cognitive and Computational Approaches. Oxford: Elsevier, pp.1-19.

Fischer, F. and Mandl, H. (2005) 'Knowledge convergence in computer-supported collaborative learning: the role of external representations tools', The Journal of the Learning Sciences, Vol. 14, No. 3, pp.405-441.

Hartup, W. and Mussen, P. (1983) 'Peer relationships', Handbook of Child Psychology. Vol. 4, pp.103-198.

Hausmann, R.G.M., Chi, M.T.H. and Roy, M. (2004) 'Learning from collaborative problem solving: an analysis of three hypothesised mechanisms', Proceedings of the 26th Annual Conference of the Cognitive Science Society. Chicago: Cognitive Science Society.

AU:

Kindly

provide editor

name for

reference

Dillenbourg

(1999) and

Otero et al. (2001).

AU:

Kindly provide editor name and publisher details for reference Hartup and

Mussen (1983).

Hawley, P. (2002) 'Social dominance and prosocial and coercive strategies of resource control in preschoolers', Int. J. Behavioral Development, Vol. 26, No. 2, p.167. 
Healey, P.G., Garrod, S., Fay, N., Lee, J. and Oberlander, J. (2002a) 'Interactional context in graphical communication', Proceedings of the 24th Annual Conference of the Cognitive Science Society. George Mason University, Virginia: Cognitive Science Society.

Healey, P.G.T., Narayanan, N.H., Lee, J. and Katagiri, Y. (2002b) 'Introduction: interactive graphical communication', Int. J. Human-Computer Studies, Vol. 57, No. 4, p.243.

Hinde, R. (1979) Towards Understanding Relationships. Academic Press.

Jones, A. and Issroff, K. (2005) 'Learning technologies: affective and social issues in computersupported collaborative learning', Computers and Education, Vol. 44, pp.395-408.

Looi, C., Seow, P., Zhang, B., So, H., Chen, W. and Wong, L. (2009) 'Leveraging mobile technology for sustainable seamless learning: a research agenda', British Journal of Educational Technology. DOI: 10.1111/j.1467-8535.2008.00912.x.

Lowe, R.K. (2003) 'Animation and learning: selective processing of information in dynamic graphics', Learning and Instruction, Vol. 13, No. 2, pp.157-176.

Otero, N., Rogers, Y. and Du Boulay, B. (2001) 'Is interactivity a good thing? Assessing its benefits for learning', Systems, Social and Internationalization Design Aspects of HumanComputer Interaction. New Jersey: Lawrence Erlbaum, pp.790-794.

Parkinson, B., Fischer, A.H. and Manstead, A.S.R. (2005) Emotion in Social Relations. Hove: Psychology Press.

Rogers, Y. and Price, S. (2009) 'How mobile technologies are changing the way children learn', in A. Druin (Ed.), Mobile Technology for Children. Morgan Kaufmann, pp.3-22.

Rogoff, B. (2003) The Cultural Nature of Human Development. USA: Oxford University Press.

Rubin, K.H. and Rose-Krasnor, L. (1992) 'Interpersonal problem solving and social competence in children' in V.B.V. Hasselt and M. Hersen (Eds.), Handbook of Social Development, Springer, pp.283-342.

Salomon, G. (1993a) Distributed Cognitions: Psychological and Educational Considerations. Learning in Doing: Social, Cognitive, and Computational Perspectives. Cambridge: Cambridge University Press.

Salomon, G. (1993b) 'No distribution without individuals' cognition: a dynamical interactional view', Distributed Cognitions: Psychological and Educational Considerations. Cambridge: Cambridge University Press, pp.111-138.

Scaife, M. and Rogers, Y. (1996) 'External cognition: How do graphical representations work?', Int. J. Human-Computer Studies, Vol. 45, No. 2, pp.185-213.

Sharples, M., Milrad, M., Arnedillo-Sanchez, I. and Vavoula, G. (2009) 'Mobile learning: small devices, big issues', in N. Balacheff, S. Ludvigsen, T. de Jong, A. Lazonder and S. Barnes (Eds.), Technology Enhanced Learning: Principles and Products. Berlin: Springer-Verlag, pp.233-249.

Spikol, D. and Milrad, M. (2008) 'Physical activities and playful learning using mobile games', Research and Practice in Technology Enhanced Learning, Vol. 3, No. 3, pp.275-295.

Sroufe, L.A. (1997) Emotional Development. Cambridge University Press.

Stahl, G. (2002) 'Contributions to a theoretical framework for CSCL', Proceedings of the CSCL 2002 Conference. Available at: http://newmedia.colorado.edu/CSCL/.

Suthers, D. and Hundhausen, C.D. (2002) 'The effects of representation on students' elaborations in collaborative inquiry', Proceedings of the CSCL 2002 Conference. Available at: http://newmedia.colorado.edu/cscl/.

Tversky, B., Morrison, J.B. and Betrancourt, M. (2002) 'Animation: can it facilitate?, Int. J. Human-Computer Studies, Vol. 57, No. 4, p.247.

Vaughn, B. and Santos, A. (2008) 'Behavioral structures governing social transactions among young children: affiliation and dominance in groups of preschool age children', in K. Rubin, W. Bukowski and B. Laursen (Eds.), Handbook of Peer Interactions, Relationships, and Groups, pp.195-214.

AU:

Kindly

provide

publisher

location for

reference

Hinde (1979),

Rogers and

Price (2009),

Sroufe (1997)

and Youniss

(1982).

AU:

kindly

provide

complete

information

for reference

Looi et al.

(2009). 
Vygotsky, L.S. (1978) Mind in Society: The Development of Higher Psychological Processes. Cambridge, MA: Harvard University Press.

Waters, E. and Sroufe, L. (1983) 'Social competence as a developmental construct', Developmental Review, Vol. 3, No. 1, pp.79-97.

Youniss, J. (1982) Parents and Peers in Social Development. University of Chicago Press.

Zhang, J.J. (1997) 'The nature of external representations in problem solving', Cognitive Science, Vol. 21, No. 2, pp.179-217. 